valent oxygen: E. E. Blaise. Ethyl ether and magnesium iodide form a well defined, crystalline compound from which the ether is only driven off when heated to temperatures approaching $190^{\circ} \mathrm{C}$. Its probable constitution is given as<smiles>CCOCCOCC</smiles>

in which the oxygen must be tetravalent. If this substance is treated with an ether containing an alkyl group of higher molecular weight, as amyl ether, the latter replaces the ethyl ether, and a vigorous reaction ensues.-On the reduction of the anhydrides of the dibasic acids: G. Blanc. The anhydrides of pyrotartaric, a -dimethylsuccinic, $\alpha \alpha$-dimethylglutaric, $\beta \beta$-dimethylglutaric, and camphoric acids, when reduced with sodium and absolute alcohol, give good yields of the corresponding lactones.-A general method for the synthesis of aldehydes with the aid of substituted glycidic acids: Georges Darzens. A mixture of monochloracetic ester with any ketone is treated with sodium ethylate in powder. The acid formed by this condensation is unstable, and splits up easily into carbon dioxide and an aldehyde of the type $\mathrm{RR}^{\prime} \mathrm{CH}-\mathrm{CHO}$, where the original ketone was $R R^{\prime}:$ CO. 'The reaction has been applied to a considerable number of ketones and found to be quite general.-On the diastatic coagulation of starch: A. Fernbach and J. Wolff. It is shown that the diastatic coagulation of starch is only possible if it is in a state of liquefaction, this being produced either by a liquefying diastase or artificially.- On the combustion of sulphur in the calorimetric bomb: H. Giran. The heat of combustion of sulphur has been determined in the Berthelot bomb at pressures varying between $2 \cdot 5$ and 45 atmospheres, with the unexpected result that the heat of formation of sulphur dioxide increases with the pressure. This result is regarded as being possibly due to the formation of the persulphuric anhydride of Berthelot.-On the electrical conductivity of collcidal solutions: G. Malfitano. In order to eliminate the effect possibly produced by the presence of minute traces of electrolytes in solution, the conductivity of the colloidal solutions was taken both before and after filtration through a thin film of collodion, it having been shown by preliminary experiments that solutions of pure electrolytes undergo no appreciable change after such filtration. It was found that the conductivity due to the fine particles in suspension was practically nil.- On the comparative production of alcohol and carbonic acid during fermentation: $M$. Lindet and P. Marsais. The ratio of alcohol to carbonic acid has been followed throughout the whole course of a fermentation, the effect of varying temperature being also studied.--Study of calcium carbide used as an explosive in mining work: Marcel P. S. Guedras. The cartridge used consisted of a charge of calcium carbide separated by an insulating membrane from water. The membrane is broken by a cap controlled electrically, and after five minutes the explosive mixture is fired also by electrical means. The explosion takes place in a manner well adapted for mining work.-On the histology of the myocardium in the primitive molluses: P. Vigier and Fr. vies.-Intranuclear fat in the suprarenal capsules of mammals: P. Mulon.-On the migration of glucosides in plants: W. Russell.-On the destruction of the winter egg of Phylloxera by lysol: G. Cantin. An account of experiments demonstrating the practical efficacy of a $\mathrm{I}$ per cent. solution of lysol against the disease.-On the mineral species of arable earth: A. Delage and H. Lagatu.-The geology of Sahel, Algeria: General de Lamothe.-The culture of the parasite of dysentery of warm countries: A. Lesage.-On infectious anæmia of the horse: MM. carrè and vallée.

\section{DIARY OF SOCIETIES}

\section{THURSDAY, JANUARY 5}

RonTGkn Soclety, at 8.15-Description of an Automatic Yacuum Pump: C E. S. Phillips. (The apparatus will be shown at w.,rk.)-Exhibition of a Method by which Strongly Adherent Films of Aluminium may be applied to Glass, - A Note on the Coloration of Gras by Radium
Radiation.

Cividiation.

Civil And Mechanical Engineers' Sociers, at 8.- Thas es Birrage:
James Casey. NO. $18 ; 6$, vOL. 7 I]
FRIDAY JANUARY 6.

InCORPORATED SOCIETY OF MEDICAL'OFFICERS OF HeAlTh, at \%.30.The Report of the Inter-Departmental Committee on Physical Degenera tion: Sir Lauder Brunton, F.R.S.

Geotogists' Associntron, at 8.-The Third Issue of the British Association Geological Photographs: Dr. C. G. Cullis.

Royal. Geographical Sơtety, at 3.30.-National Antarctic Expedition : Capt. R. F. Scott. (Lecture to Young People.)

MONDAY, JANUARY 9 .

Soctety of Chemical Inoustry, at 8.-Some Chemical Aspects of the SocteTy of Couis Exhibition: Walter F. Reid.

Roval Geographical. Society, at 8.30.-Mr. Reginald Enocks Journeys in Peru: the President.

$$
\text { TUESDAY, JANUARY IO. }
$$

Institution of CiviL Engingers, at 8.-The Recent Visit to the United States and Canada: Sir William Henry White, K.C.B. (The Address will be repeated on the following day at 3.30 p.m.) WEDNES $D A Y$, JANUARY $\mathrm{r}$.

Society of Public Analysts, at 8.-Brandy: Otto Hehner. THURSDAY, JANUARY 12.

Mathematical Society, at 5.30.- Generational Relations for the Abstract Group simply Isomorphic with the Abstract Group LF $\left[2, p^{n}\right]$; Dr. W. Bussey.-On a Class of Expansions in Oscillating Functions: Prof A. C. I ixon. - Isogonal Transformation and the Diameter Transformation: H. L. Trachtenberg.-A Generalisation of the Legendre Poly nomial: H. Bateman-Current Flow in Rectangular Conductors :
H. Fletcher Moulton.-Basic Generalisations of some well known Analy tic Functions: Rev. F. H. Jackson.

\section{CONTENTS.}

PAGE

Modern Optical Methods. By Prof. G. H. Bryan,

F.R.S

American Cytology. By H. H. D. . . . . . . . 218

Physical Research at Leyden . . . . . . . . . 218

Practical Silicate Analysis . . . . . . . . . . . . . . . . . . 2 . 219

Our Book Shelf :-

Lassar-Cohn and Tingle: "Application of some General Reactions to Investigations in Organic Chemistry."-J. B. C.

Leonard and Salmon : "A Further Course of Practical Science"

Eichhorn : "Die drahtlose Telegraphie" * * * . 220

Campbell: "Notes on the Natural His' ory of the Bell Rock."--R. L. . "The British Journal Photographic

Bedding : "The British Journal Photographic Letters to the Editor:-

Mean Temperatures of High Southern Latitudes. Prof. Julius Hann .. . . . . . . . . . . Reversal of Charge from Electrical Induction Machines.-George W. Walker . . . . . . 221

Fishing at Night.-F. G. Aflalo . . . 22 I

The Cost of Chemical Synthesis. . R. J. Friswell $\quad 22$

"Bastard" Logwood.-S. N. C. . . . . . . . . 222

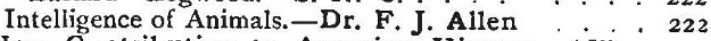

A New Contribution to Assyrian History. (Iilustrated.)

Seismology in Japan. (Illustrated.) . . . . . . . 22

The Founder of Australian Antbropology. (Illustrated.) By A. Ernest Crawley . . . . . . . . .

Changes Upon the Moon's Surface. (Iilustrated)

By Prof. William H. Pickering . . . . . . 226

Sir Lowthian Bell, Bart., F.R.S. . . . . . . . . . 230

Notes . . . . . . . . 230

ur Astronomical Column:-

Another New Comet (I904e) . . . . . . . . . . 233

Comet I904 $d$ (Giacobini) . . . . . . . . . . . . 233

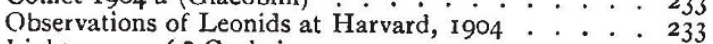

I ight-curve of $\delta$ Cephei . . . . . . . . . . . . . . 234

Structure of the Third Cyanogen Band . . . . . . . 234

New Refaction Tables . . . . . . . . . . . 234

The "Annuaire" du Bureau des Longitudes . . . . 234

Eclipse Results and Problems . . . . . . . . . 234

Bibliography of Contemporary Astronomical Works . 234

Prizes Proposed by the Paris Academy of Sciences for I 905

Geological Notes. (Illustrated.) . . . . . . . . . . 234

Agricultural Education and Research. By Prof. T. H. Middleton

Scientific Reports of the Local Government Board. By Prof. R. T. Hewlett . . . . . . . . . . 237

University and Educational Intelligence . $.^{*}+{ }^{*} 238$

Socjeties and Academies . . . . . . . . . . . 238

Diary of Societies ................ . . . . . . 240 